\title{
Incidence of venous thromboembolism in France: a retrospective analysis of a national insurance claims database
}

\author{
Stéphane Bouée ${ }^{1 *}$, Corinne Emery ${ }^{1}$, Adeline Samson ${ }^{2,3}$, Julie Gourmelen ${ }^{4}$, Cécile Bailly ${ }^{3}$ and François-Emery Cotté ${ }^{3}$
}

\begin{abstract}
Background: Data estimating the annual incidence of venous thromboembolism (VTE) in France, taking into account both hospital and community settings, are very lacking.

This study aimed to estimate the annual incidence of VTE (pulmonary embolism (PE) and deep vein thrombosis (DVT)) in France in 2011 in "real world" population.

Methods: This was a longitudinal insurance claims study of the incidence of VTE in France over 2 years (2010 and 2011). The data analysis was performed using the EGB (Echantillon Généraliste des Bénéficiaires) database, a randomly selected sample of the French national insurance database (CNAMTS) which covers $77 \%$ of the population. All adult patients experiencing a VTE event during the study period were analysed. Recurrence rate of VTE and all-cause mortality rate were also estimated over a 12-month follow-up period.
\end{abstract}

Results: The estimated annual incidence of VTE in France was 184.0 per 100000 subjects, corresponding to a total of 119670 events countrywide. The estimated incidence of DVT and PE were respectively 119.8 and 64.2 per 100000 subjects. Annual recurrence of VTE was reported in $5.5 \%(n=99)$ patients, with a significantly higher recurrence rate in patients with PE than those with DVT $(p=0.02)$. Overall, $6.2 \%(n=112)$ of patients had died over the 12-month follow-up (respectively 10.2 and $7.7 \%$ of patients with DVT and PE).

Discussion: To our knowledge, this analysis is the first to estimate the annual incidence of VTE in France using exhaustive data from the EGB database. This has allowed the incidence of DVT in the community to be documented, which to date has not been characterised. Previous studies in France have been limited to the hospital setting and have yielded incidence rates comparable to ours.

Conclusions: This analysis is the first to estimate the annual incidence of VTE in France using exhaustive data from the EGB database. This study showed that the incidence and the burden of the disease remains elevated.

Keywords: Incidence, Deep vein thrombosis, Pulmonary embolism, Recurrence, France

\section{Background}

Venous thromboembolism (VTE) is a common condition presenting as deep vein thrombosis (DVT) or pulmonary embolism (PE). DVT of the lower limbs is a potentially lifethreatening disease which may be asymptomatic or symptomatic (leg pain, swelling). PE often follows previously asymptomatic DVT and may be revealed by breathlessness, faintness, chest pain, collapse or sudden death. In addition to these short term consequences, long term complications

\footnotetext{
* Correspondence: Stephane.Bouee@cemka.fr

${ }^{1}$ Cemka, 43 bd du Maréchal Joffre, 92340 Bourg-la-Reine, France

Full list of author information is available at the end of the article
}

of VTE exist including post-thrombotic syndrome and pulmonary hypertension [1]. Timely detection and management of VTE is important due to the clinically silent nature of VTE in around $80 \%$ of patients [2], its high prevalence in at-risk patients and its potentially life-threatening nature. In a large, population-based survey performed in the US, the mortality rate in hospitalised patients experiencing a VTE was $12 \%$ [3].

VTE is considered as the third most common cardiovascular condition after myocardial infarction and stroke and is a growing public health problem due largely to the ageing population [1]. In a multinational survey performed in 32 
countries around the world and enrolling 68183 patients [4], more than half (51.8 \%) of hospitalised patients aged 40 years or over were judged to be at risk for VTE. In North America and Europe, the annual incidence of VTE is estimated to be approximately 160 per 100,000 for DVT, 20 per 100,000 for symptomatic non-fatal PE and 50 per 100,000 for fatal autopsy-detected PE [5]. In France, the incidence of VTE has been estimated in community-based study in Western Brittany performed in 1998-1999 [6] and, more recently, another nationwide study has estimated the incidence of VTE in hospitalised patients to 186.6 per 100000 subjects [7].

Recently, a number of novel oral anticoagulant agents (NOACs) have been approved for the treatment of VTE. In the context of the introduction of these new therapies, it is important to collect up-to-date and comprehensive data on the burden of VTE in France. This information will be important in order to evaluate the cost-effectiveness of such treatments. To our knowledge, no studies have been published in the last decade that have estimated the incidence of VTE in France, taking into account both hospital and community settings. Recently, a number of public health insurance databases have become available in France which have made it possible to conduct longitudinal nationwide epidemiological and economic analyses providing quasiexhaustive information on healthcare resource utilisation. This provides an opportunity to reassess the incidence, mortality and morbidity of VTE at a national level. The sponsor of the present study, who markets a NOAC (apixaban) in France, was required by the local regulatory authorities to provide information on the size of the potential target population before introduction of this drug. For this reason, we conducted an analysis of VTE events documented in the EGB (Echantillon Généraliste des Bénéficiaires) database, a representative sample of the French national insurance which covers more than threequarters of the French population [8].

The objectives of this study were to estimate the annual incidence rate of primary VTE (PE and DVT) in 2011 in France in both hospital and community care settings, and to estimate the 12-month incidence rate of recurrent VTE events.

\section{Methods}

This was a longitudinal insurance claims study of the incidence of VTE in France over 2 years (2010 and 2011).

\section{Data source}

The study used data provided by the French health insurance fund for salaried workers (Caisse Nationale d'Assurance Maladie des Travailleurs Salariés (CNAMTS)). The CNAMTS database includes all salaried workers and their relatives and covers $77 \%$ of the French population in 2011 (almost 50 million people). Individuals remain covered by the same fund if they stop working for any reason, including retirement, unemployment, invalidity or long-term sick leave. The self-employed, civil servants, students and agricultural workers are the principal socioprofessional groups not insured by the CNAMTS. This database contains comprehensive reimbursement records which documents all items of medical consumption in the public or private sectors eligible for reimbursement by public health insurance [8].

The data analysis was performed using the EGB database, which represents a permanent sample of individuals selected at random from $1 / 97^{\text {th }}$ of all beneficiaries of the CNAMTS and provides data of around 600000 individuals representative of the French population. This database was developed in 2005 in order to facilitate the conduct of longitudinal epidemiological and economic analyses which are important for planning of healthcare resource attribution [9]. The EGB database contains anonymous information on demographics (age and gender). All eligible medical expenditure reimbursed for a given individual is linked through a unique patient identifier. Items which are not eligible for reimbursement, such as OTC drugs, are absent from the database and cannot be identified. For each prescribed or reimbursed service, the date of implementation is specified, together with the date of prescription and the healthcare provider. No explicit information is provided for the reason for which the service was prescribed, for example the diagnosis. However, in the case of hospitalisations, and only in this case, the diagnosis can be identified since each hospital stay is valued on the basis of a unique diagnosis-related group (DRG) which is coded using the international classification of disease (ICD-10) codes. The reasons for hospitalisation are coded either as primary diagnoses (the condition for which the patient was hospitalised) or as associated diagnoses (comorbidities which may affect the course of hospitalisation). Information on deaths is available in the database but the cause of death is not documented [9]. The EGB database is updated every month.

\section{Identification of patients with DVT or PE}

The target population of the present study consisted of all adult patients with PE or DVT identified in both hospital and community care between 2010 and 2011 documented in the EGB database. For hospitalised patients, patients with PE or DVT were identified from the ICD-10 codes used to assign the DRG associated with the hospital stay (either as a primary or associated diagnosis). The ICD-10 codes used to assign diagnosis were I80.1-9 or I82.1-9 for DVT and I26.0 or I26.9 for PE.

In community care, it was not possible to identify patients with DVT or PE directly from the EGB database since there is no information on diagnosis. For this reason, we constructed an algorithm to identify these patients with 
DVT from the medical services used. The algorithm for community DVT takes into account three criteria:

1. Reimbursement of an Echo-Doppler exam (day 0: T0)

2. Delivery of a LMWH or fondaparinux (T0 \pm 7 days)

3. Delivery of a subsequent Vitamin K antagonists ( $\mathrm{T} 0+7$ days)

Subjects were considered to have a DVT if they fulfilled all these criteria in the above order.

We assumed that all subjects with a confirmed PE were immediately hospitalised and were thus captured through the hospitalisation records.

\section{Data collection}

From the EGB database, we collected the date of all VTE events (PE or DVT) occurring between 2010 and 2011. For each patient, this date was considered to be the index date. The age and gender of each patient was documented. A retrospective analysis of all reimbursement claims over the 12 months preceding the index date was performed. From this data, information on the presence of risk factors for DVT such as orthopaedic surgery and comorbidities were extracted. In addition, reimbursement claims were also evaluated in the 12 months following the index VTE to document all pertinent medical events. These included recurrence of DVT in the community, (defined by the algorithm), hospitalisation for PE, DVT, myocardial infarction, ischaemic stroke, haemorrhage, pregnancy, post-thrombotic syndrome, arterial and pulmonary hypertension. All-cause hospitalisation and death during the 12-month follow-up period were also documented.

\section{Estimation of incidence}

The analysable population consisted of all adult patients experiencing a VTE event during the study period. Study variables were described in the total patient population. All VTE events occurring during the 2-year evaluation period was considered for the estimation of incidence. If an episode of DVT evolved into a PE (clot migration), then the event was considered as an index PE only. Patients who were diagnosed with a VTE in the community and subsequently hospitalised were considered as hospitalised with respect to the index VTE. The incidence of VTE was estimated using EGB database and then extrapolated to the whole French population in 2011 (65 026885 individuals [10]).

\section{Data analysis}

Continuous data were expressed as mean \pm standard deviation and median [range: min-max]. Categorical data were presented as frequency counts (\%) with their $95 \%$ confidence intervals.

Incidence of recurrent VTE events (PE and DVT) and other events such as post-thrombotic syndrome, pulmonary hypertension, myocardial infarction, ischemic stroke and bleedings were defined as frequency rates of patients experiencing a new event during the 12-month follow-up period consecutive to the diagnosis of the primary VTE. The cumulative incidence of recurrence of VTE was estimated using Kaplan-Meier survival analysis. The mortality rate was also estimated in this way.

A regression analysis (Cox model) was performed in order to identify factors associated with recurrence of VTE. In a first step, a list of possible factors was identified, including demographics, hospitalisation in the past 3 months, trauma, comorbidities (cardiovascular disease, tumours, renal disease), gastro-intestinal haemorrhage and obesity. Each variable was first evaluated independently in a univariate analysis. In a next step, all factors correlated with recurrence of VTE (at a probability level of 0.05 ) in the univariate analysis were entered into a multivariate regression analysis in order to identify those independently associated with recurrence of VTE at a probability level of 0.05 . In addition, a regression logistic analysis was also performed in order to identify factors associated with hospitalisation for DVT. All identified factors in the univariate analysis were then entered into a multiple regression logistic analysis in order to identify those independently associated with hospitalisation for DVT at a probability level of 0.05 . The variables finally retained were entered into a multivariate model to generate odd ratios.

\section{Ethics}

The study was performed in accordance with the International Society for Pharmacoepidemiology (ISPE) Guidelines for Good Pharmacoepidemiology Practices (GPP) and applicable regulatory requirements. Since data was not nominative and was collected retrospectively, ethics board approval was not required. Use of the EGB database was approved by the French national data protection agency (CNIL).

\section{Results \\ Incidence of VTE}

The number of VTE events recorded in the EGB database between 2010 and 2011, and the corresponding incidence are presented in Table 1.

The estimated annual incidence of VTE was 184.0 per 100000 subjects, which corresponds to an estimated annual number of 119670 events in France. The estimated incidence of DVT was 119.8 per 100000 subjects, corresponding to an annual number of 77903 events. With respect to $\mathrm{PE}$, the estimated incidence was 64.2 per 100 000 subjects, which corresponds to a total of 41767 events in France. The incidence of both DVT and PE in hospital environment is similar (Table 1). 
Table 1 Incidence of VTE in France between 2010 and 2011

\begin{tabular}{llll}
\hline Type of VTE event & $\begin{array}{l}\text { Number of VTE events } \\
\text { in the EGB }\end{array}$ & $\begin{array}{l}\text { Annual incidence (/100 000 } \\
\text { subjects; [Cl 95 \%]) }\end{array}$ & $\begin{array}{l}\text { Extrapolation to French population } \\
\text { (number of events) }\end{array}$ \\
\hline PE & 675 & $64.2[57.4-71.1]$ & 41767 \\
DVT (hospital) & 673 & $64.0[57.2-70.9]$ & 41643 \\
DVT (comm-care) & 586 & $55.8[49.4-62.1]$ & 36260 \\
\hline
\end{tabular}

${ }^{a}$ One patient can have $\geq 1$ VTE event

\section{Characteristics of the study population}

Over the study period (2010 and 2011), a total of 1804 patients with VTE were identified in the EGB database and these constituted the analysis population. Overall, a DVT was identified in 1182 (65.5\%) patients, with approximately equal numbers of patients identified in hospitals (633 patients; $53.5 \%$ ) and in community care (549 patients; $46.6 \%$ ) (Table 2). Pulmonary embolism was identified in $622(34.5 \%)$ patients. It was possible to identify the localisation of DVT for 334 hospitalised patients and this was distal DVT in the majority of cases (283; $84.7 \%$ patients).

The characteristics of the study population are presented by setting in Table 2 . The distribution of the study population with respect to gender is comparable between patients with PE and those with DVT, with a slight but not significant over-representation of women. The mean age was 65 years. Hospitalised patients with DVT or PE were older than patients with DVT in community care $(p<0.0001)$. Overall, $13.5 \%$ of patients had been hospitalised in the previous year. Around half of the study population present at least one risk factor for VTE, most frequently cancer. Hormonal therapy was prescribed in nearly ten percent of patients with DVT or PE.

Among patients with DVT identified in the community care setting $(n=549)$, echography, heparin therapy and VKA were principally prescribed by general practitioners $(78.9,87.0$ and $88.4 \%$ of cases respectively). Prescriptions by hospital-based physicians concerned $<7 \%$ of patients (5.3, 6.6 and $6.0 \%$ of cases respectively).

\section{Recurrence of VTE}

During the 1-year follow-up of patients identified with an index VTE ( $n=1804$ patients), a total of 99 patients (5.5 \%; [95 \% CI: 4.5-6.6 \%]) experienced a recurrent VTE, most frequently a PE $(n=47$ patients; $47.5 \%)$ (Table 3). Recurrence of PE was significantly higher than recurrence of DVT $\left(p=0.02 ; \mathrm{X}^{2}\right.$ test). Recurrence of DVT over the follow-up period was similar irrespective of the treatment setting (hospital or community care). In the majority of cases, only one recurrence of the index event (PE or DVT) was identified during the follow-up period.

Table 2 Demographics and medical history of the study population

\begin{tabular}{|c|c|c|c|c|}
\hline & \multirow{2}{*}{$\begin{array}{l}\text { Patients } \\
\text { with PE }\end{array}$} & \multicolumn{2}{|c|}{ Patients with DVT } & \multirow[t]{2}{*}{ Total } \\
\hline & & Hospital & Community care & \\
\hline Number of patients (N, (\%)) & $622(34.5 \%)$ & $633(35.1 \%)$ & $549(30.4 \%)$ & $1804(100 \%)$ \\
\hline Gender (\% women) & $57.3 \%$ & $69.6 \%$ & $54.5 \%$ & $57.2 \%$ \\
\hline \multicolumn{5}{|l|}{ Age (years) } \\
\hline Mean \pm SD & $67.0 \pm 17.2$ & $67.5 \pm 17.7$ & $60.3 \pm 16.9$ & $65.1 \pm 17.6$ \\
\hline Median [Min-Max] & 71 [19-99] & 71 [18-99] & $61[21-94]$ & 68 [18-99] \\
\hline \multicolumn{5}{|c|}{ At least one risk factor of VTE (N, (\%)) } \\
\hline Yes & $320(51.4 \%)$ & $338(53.4 \%)$ & $159(29.0 \%)$ & $817(45.3 \%)$ \\
\hline No & $302(48.6 \%)$ & $295(46.6 \%)$ & $390(71.0 \%)$ & $987(54.7 \%)$ \\
\hline \multicolumn{5}{|l|}{ Principal risk factors (N, (\%)) } \\
\hline Hip fracture & $2(0.3 \%)$ & $2(0.3 \%)$ & $1(0.2 \%)$ & $5(0.3 \%)$ \\
\hline Pregnancy & $9(1.4 \%)$ & $7(1.1 \%)$ & $3(0.5 \%)$ & $19(1.1 \%)$ \\
\hline Surgery & $26(4.2 \%)$ & $24(3.8 \%)$ & $19(3.5 \%)$ & $69(3.8 \%)$ \\
\hline Trauma & $41(6.6 \%)$ & $54(8.5 \%)$ & $17(3.1 \%)$ & $112(6.2 \%)$ \\
\hline Hospitalisation & $92(14.8 \%)$ & $112(17.7 \%)$ & $40(7.3 \%)$ & $244(13.5 \%)$ \\
\hline Hormonal therapy & $54(8.7 \%)$ & $37(5.8 \%)$ & $58(10.6 \%)$ & 149 (8.3 \%) \\
\hline Cancer & $129(20.7 \%)$ & $135(21.3 \%)$ & $43(7.8 \%)$ & $307(17.0 \%)$ \\
\hline Obesity & 31 (5.0\%) & $44(7.0 \%)$ & $18(3.3 \%)$ & $93(5.2 \%)$ \\
\hline
\end{tabular}


Table 3 Recurrence of VTE during 1-year follow-up period

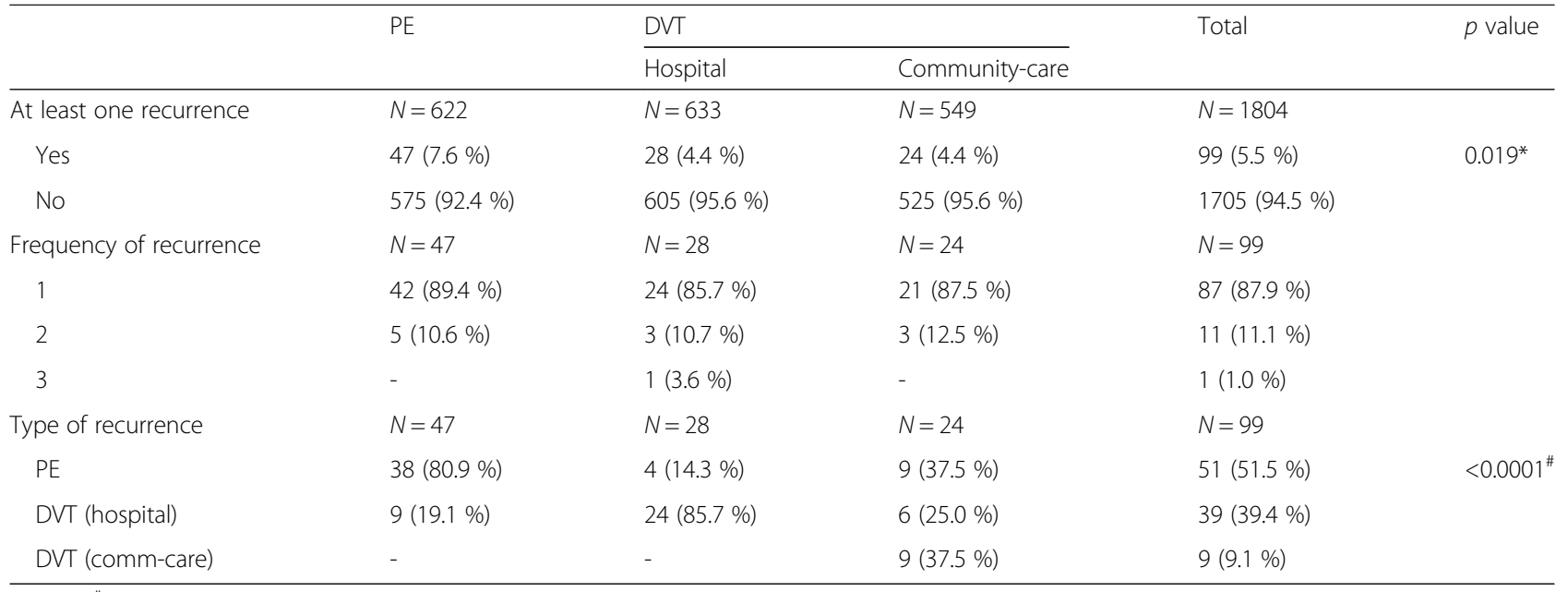

${ }^{*} \times 2$ test. ${ }^{*}$ Fisher's exact test

The cumulative incidence of recurrence of VTE during the 1-year follow-up period was estimated at $2.3 \%$ [95 \% CI: 1.6-3.0 \%] at Month 1, 3.2 \% [95 \% CI: 2.4$4.0 \%$ ] at Month 3, $4.3 \%$ [95 \% CI: 3.3-5.2 \%] at Month 4 and $5.2 \%$ [95 \% CI: 4.2-6.2\%] at Month 9 (Fig. 1a). The time-course of recurrence of DVT was again similar in the two treatment settings (Fig. 1b). The 1-month and 3-month recurrence rates for PE were 3.2 and $5.0 \%$, and for DVT were 1.9 and $2.4 \%$.

A regression analysis (Cox model) was performed in order to identify factors associated with recurrence of VTE. The only factor which was correlated with recurrence of VTE during the 1-year follow-up period was hospitalisation for renal failure (data not shown).

\section{Mortality}

Overall, $6.2 \%$ [95 \% CI: 5.1-7.3\%] $(n=112)$ of patients had died by the end of the 12-month followup $(0.2 \%$ [95 \% CI: 0-0.4\%] at Month 1, $1.1 \%$ [95 \% CI: 0.6-1.5 \%] at Month 3, $2.5 \%$ [95 \% CI: $1.8-3.3 \%$ ] at Month 6 and $4.3 \%$ [95 \% CI: 3.4-5.3\%] at Month 9) (Fig. 2a). The mortality rate was $7.7 \%$ [95 \% CI: 5.6$9.8 \%$ ] $(n=48)$ in patients with PE, $9.3 \%$ [95 \% CI: $7.0-11.6 \%](n=59)$ in patients with DVT in hospitals and $0.9 \%$ [95 \% CI: $0.0-1.7 \%$ ] $(n=5)$ in patients with DVT in community care. The mortality rate was significantly higher in hospitalised patients with DVT than those managed in community care $(p<0.001)$ (Fig. 2b).
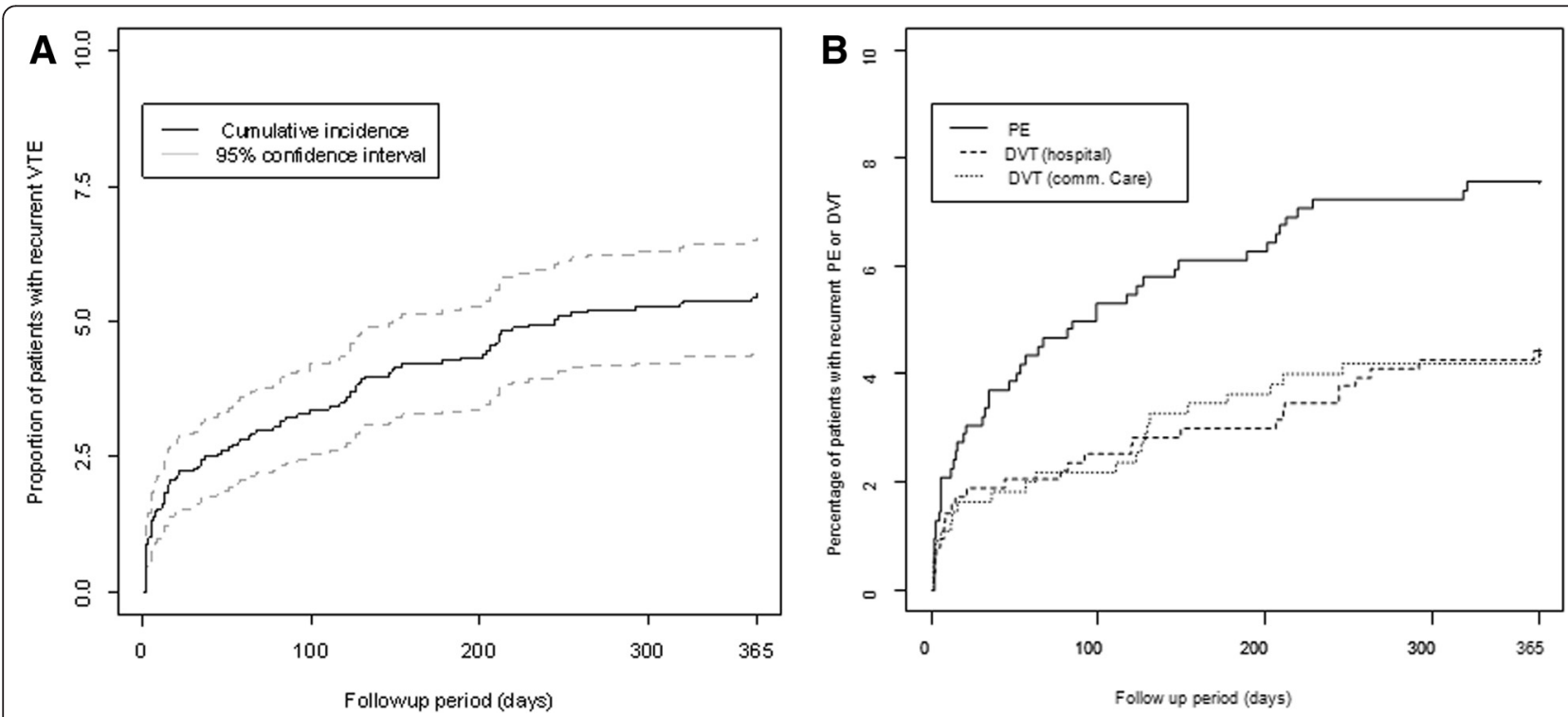

Fig. 1 One-year cumulative incidence of recurrences of VTE. a: all recurrence events; $\mathbf{b}$ : recurrence by VTE type 

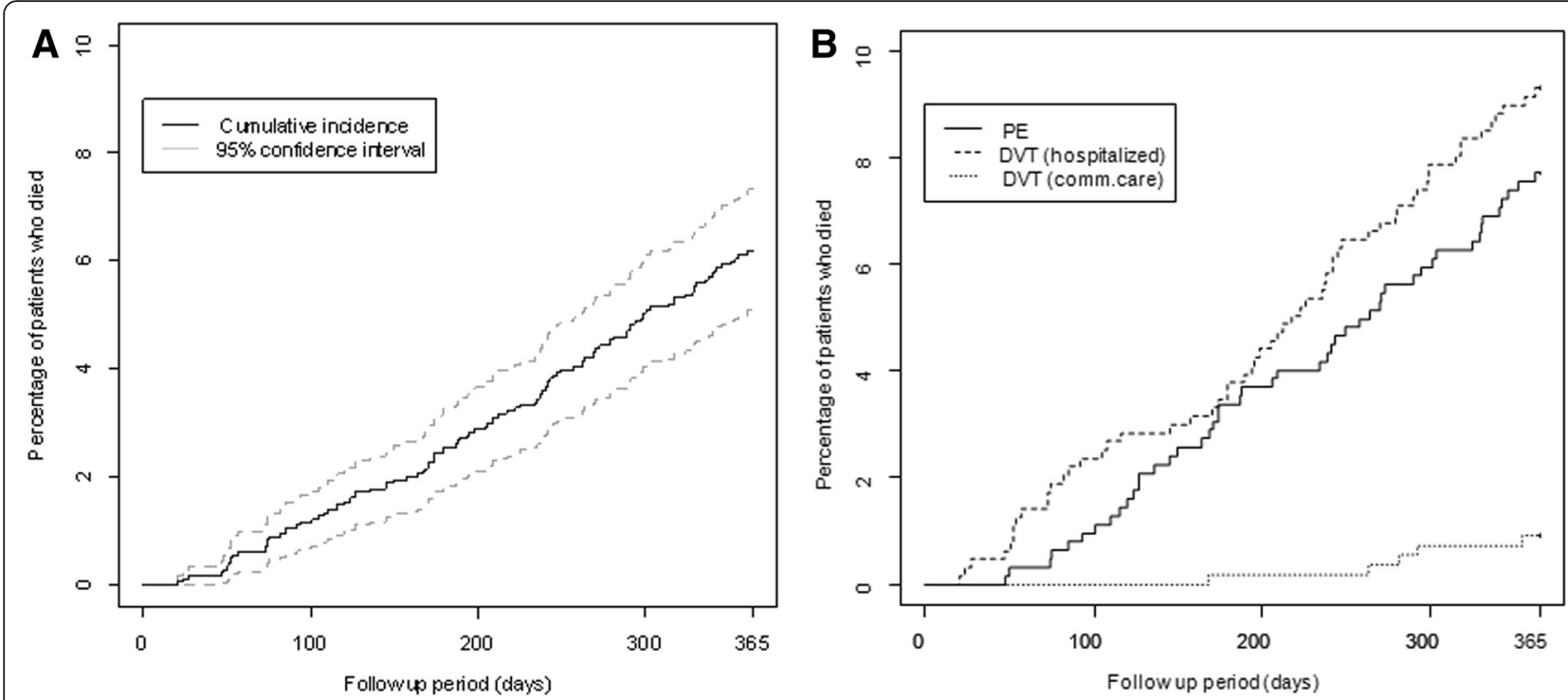

Fig. 2 Cumulative incidence of death during the 12-month follow-up a: all deaths; b: deaths by VTE type

\section{Determinants of hospitalisation for a DVT}

A regression analysis (logistic model) was performed in order to identify factors associated with hospitalisation for the index DVT. Hospitalisation for DVT was significantly associated with age $\geq 60$ years, previous all-cause hospitalisation, presence of tumour, heart failure, renal disease, previous hospitalisation for DVT and gastrointestinal haemorrhage (Fig. 3).

\section{Discussion}

This retrospective study documented the incidence of VTE (PE and DVT) in France in 2010 and 2011 based on national health insurance claims data. To our knowledge, this analysis is the first to estimate the annual incidence of VTE in France using exhaustive data from the EGB database, allowing the poorly-documented issue of DVT in community care to be addressed. The annual incidence of VTE in France in 2011 was estimated to 184.0 per 100000 subjects. The estimated incidence of DVT was 119.8 per 100000 subjects, corresponding to a total of 77903 events. The estimated incidence of PE was 64.2 per 100000 subjects, which corresponds to a total of 41767 events countrywide. It should be noted that since the study was performed from an insurance claims database, patients with VTE who were either undiagnosed or untreated will not be identified.

The estimated incidences of DVT and PE in our study may be compared with previous estimations in France. For example, a community-based epidemiological study performed by a network of hospital and community physicians in Western Brittany in 1998-1999 [6] estimated annual incidence rates of 124 per 100000 subjects for DVT and 60 per 100000 subjects for PE, corresponding to 110000 patients experiencing a VTE in France per year, of whom $33 \%$ were diagnosed outside the hospital. Other studies in France have been limited to the hospital setting and have yielded incidence rates globally comparable to ours [11]. Notably, the estimated incidence of VTE in hospitals found in our study (128.2 per 100000 subjects), is relatively comparable with the results of a recent study of the national hospitalisation database which estimated the incidence of VTE (as primary diagnoses or as associated diagnoses) in hospitalised patients to 186.6 per 100000 subjects [7].

With respect to demographics, the analysable patients are comparable with the population of the international RIETE registry which includes in 2008 a total of 8053 patients with symptomatic, objectively confirmed and acute VTE in Spain [12]. Nevertheless, in our study women are over-represented compared to enrolled patients in large and recent randomised clinical trials on VTE [13-16], in which women represented from 42 to $46 \%$ of the total population. This difference may be explained by the fact that overall the proportion of women is admitted to be underrepresented in the majority of randomised clinical trials.

Our study revealed that over 1-year of follow-up, recurrence of VTE was reported in $5.5 \%$ patients. This result is comparable with other estimations in France or in Western countries in which recurrence of VTE occurred in between 5 and $10 \%$ of patients during the first 2 -years [17-20]. In addition, data from the RIETE registry including 6361 patients with VTE reported that recurrence of VTE occurred in $3.0 \%$ of patients after 3 months of follow-up [21], which is similar to our estimation (3.2\%). The only factor found to be associated 


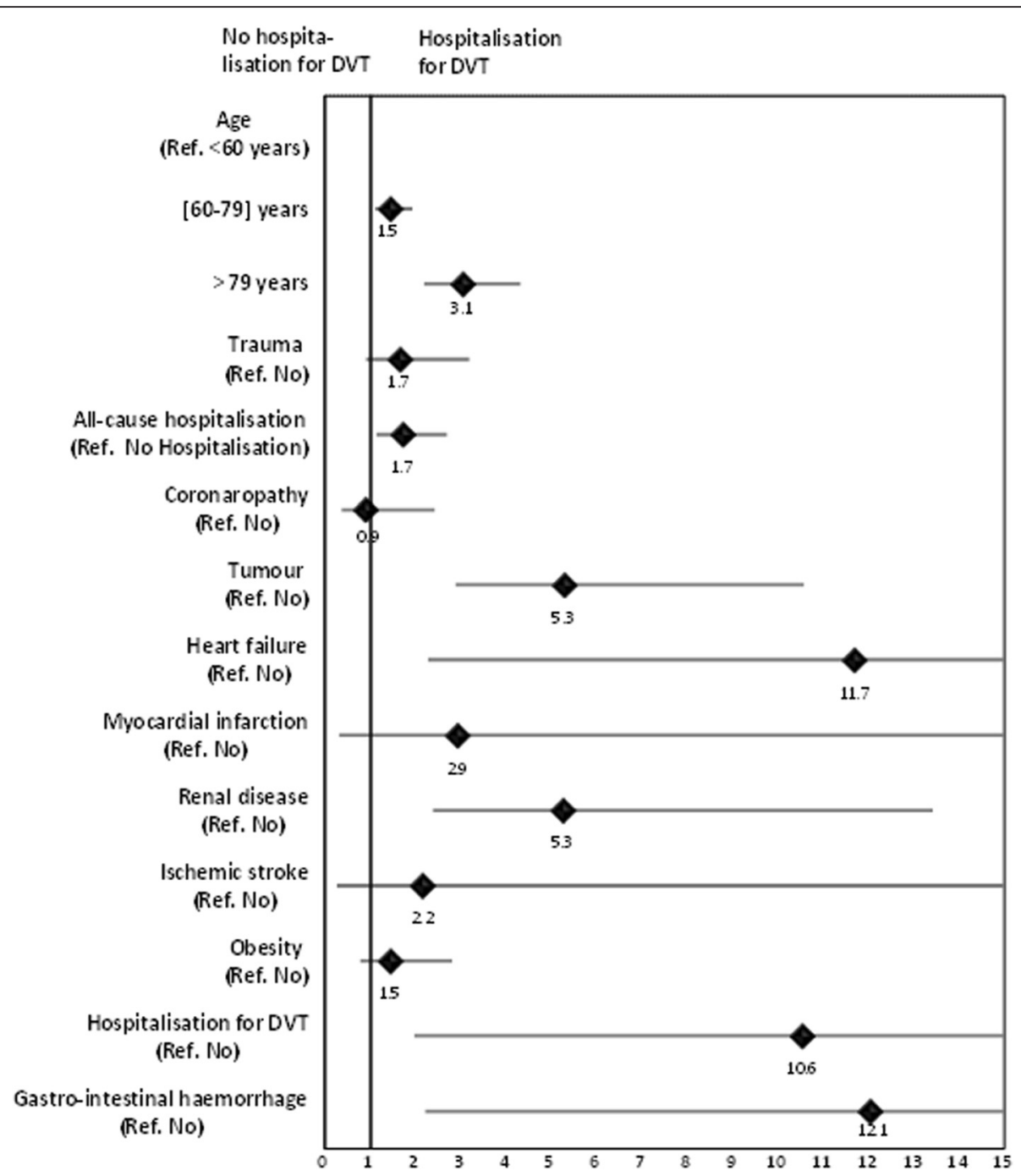

Fig. 3 Factors associated with hospitalisation for DVT identified by multiple regression analysis

with recurrence was hospitalisation for renal failure. It has been reported in the literature that the risk of recurrent VTE may vary according to age and gender [19, 22, 23], but we were not able to identify any such association in our study.

After 1-year of follow-up, the mortality rate among patients with VTE was estimated in our study at $6.2 \%$. We found the mortality rate to be higher, without a statistically significant difference, in hospitalised patients with DVT than in patients with PE. This finding was surprising given that $\mathrm{PE}$ is generally considered to be associated with a higher recurrence rate and to be potentially most lethal than DVT. One potential explanation for this finding is that PE episodes causing immediate death will not be captured since subjects were not hospitalised or previously diagnosed with $\mathrm{PE}$. It was reported in a study performed in community-care in the UK in 2007 that of 730 fatal cases of VTE, ninety percent related to death on the date of diagnosis of PE [24]. Moreover, the 3month fatality rate after PE seems to be underestimated $(0.8 \%)$ in our study compared to the literature. For example, in the OPTIMEV study the 3-month mortality rate was estimated to be $12.9 \%$ in patients with PE secondary to DVT and $4.6 \%$ in patients with primary PE [25]. Again, this may be attributed to failure to capture immediately fatal VTE events. A striking finding of the study was that the mortality rate after DVT was tenfold higher in hospitalised patients than those managed in community-care environment $(9.3 \%$ versus $0.9 \%$ respectively). It should be noted that no information on the cause of death is provided in the EGB database, and to what extent the deaths reported can be attributed directly or indirectly to VTE is unknown.

This study also allowed us to assess factors potentially associated with the care setting, which distinguished between patients with DVT managed in the hospital and 
those managed in community-care. Several such determinants of hospitalisation were identified, including older age, previous all-cause hospitalisation, presence of tumours, heart failure, renal disease, previous hospitalisation for DVT and gastro-intestinal haemorrhage. Taken together, this suggests that hospitals take care of the more fragile patients. These factors are consistent with guidelines from the French Health agency (ANSM) for the management of DVT in hospitals [26]. Nonetheless, around half of the patients with DVT were managed in the community and this proportion is higher than that reported a decade previously in the survey in Brittany (France) [6]. This evolution may reflect better understanding of VTE and its management by community-based physicians and represents potentially important economies for the health service.

This study provided little information about treatment of DVT. By definition, all community DVT patients identified in our study were treated with a heparin followed by a VKA. International and French treatment guidelines for hospitals recommend acute treatment of VTE with heparins followed by pharmacological prophylaxis with VKA to prevent recurrence [26-28]. During the observation period of the study, NOACs had not yet been made available in France. Moreover, in addition to the known risk factors associated with recurrence of VTE such as previous hospitalisation or cardiovascular diseases, recurrence of VTE will also depend on VTE prophylaxis after the index event. For example, in the pivotal studies of new oral anticoagulants, the recurrence rate was somewhat different between treatment groups and ranged from 1.3 to $9.8 \%$ of patients $[13,14,29,30]$.

The incidence of VTE observed in this study may be expected to change over the coming years due to the introduction of new treatments, notably non-VKA oral anticoagulant drugs. These have been shown to reduce the risk of VTE and PE [16], as well as other serious vascular events such as stroke [31] and acute coronary syndrome [32, 33].

The study presents a number of strengths. The most important of these is the exhaustiveness of the data available in the EGB database, which at the time of the study, provided information on a random sample of $77 \%$ of the French population [8]. The EGB sampling method is based on a national identifier attributed to each French resident which allows all health care consumption to be followed until death. However, this database has some limitations for this type of epidemiological study. Data analysis is retrospective, as is usual for insurance claims studies, and this restricts the analysis to information routinely documented in the database. In community care, no information on diagnosis is available and the reasons for prescription of medication and medical procedures are not documented, either in hospital or in community care. In this respect, a notable and novel feature of the study was the design of a specific algorithm to identify patients with DVT in the community from insurance claims records. For hospitalised patients, incomplete or erroneous documentation of DRGs, and thus diagnoses, cannot totally be excluded since there was no possibility for case ascertainment through the medical records. Finally, we made the assumption that all cases of PE were managed in hospitals, but it cannot be excluded that some patients with $\mathrm{PE}$ in the community have not been diagnosed correctly. There is thus some uncertainty in our estimations, in particular for DVT events managed out of hospitals. Another limitation is that the EGB database does not capture information about clinical reasons for death and consequently we cannot estimate the specific VTE-related mortality rate in our study.

\section{Conclusion}

Primary VTE (PE and DVT) affects around 120,000 individuals in France each year, of whom one in twenty has a recurrent VTE and one in sixteen dies within the following year. The burden of the disease remains elevated, in spite of effective treatments and better understanding of risk factors and their prevention. The number of patients with DVT managed in the community increases, particularly in the less vulnerable patients, and this is associated with better long-term outcome.

\section{Competing interests}

AS, CB and FEC are employees of BMS. SB and CE are employees of CEMKA Eval, a Health Economics Consultancy, who received fees from BMS for data management and data analyses. JG is an employee of INSERM (French Institute of Health and Medical Research).

\section{Authors' contributions}

SB and FEC developed the hypotheses and conceived the analysis plan. CE and JG performed the statistical analyses. All authors have had full access to data and contributed to the analysis and interpretation of the study results.

All authors participated in the preparation and the revision of the

manuscript and agree to be accountable for all aspects of the work. All authors approved the submission of this final draft.

\section{Acknowledgments}

Funding for the study was provided by Bristol-Myers Squibb and Pfizer France, purveyors of apixaban, indicated for the prevention of VTE.

\section{Author details \\ ${ }^{1}$ Cemka, 43 bd du Maréchal Joffre, 92340 Bourg-la-Reine, France. ${ }^{2}$ Paris-Dauphine University, Paris, France. ${ }^{3}$ Bristol-Myers Squibb, Rueil-Malmaison, France. ${ }^{4}$ INSERM UMS 011, Villejuif, France.}

Received: 18 June 2015 Accepted: 16 November 2015

Published online: 19 February 2016

\section{References}

1. Goldhaber SZ, Bounameaux H. Pulmonary embolism and deep vein thrombosis. Lancet. 2012;379(9828):1835-46.

2. Pendleton $\mathrm{R}$, Wheeler $\mathrm{M}$, Rodgers $\mathrm{G}$. Venous thromboembolism prevention in the acutely III medical patient: A review of the literature and focus on 
special patient populations, vol. 79. New York, NY, ETATS-UNIS: Wiley-Liss; 2005.

3. Anderson Jr FA, Wheeler HB, Goldberg RJ, Hosmer DW, Patwardhan NA, Jovanovic B, et al. A population-based perspective of the hospital incidence and case-fatality rates of deep vein thrombosis and pulmonary embolism. The Worcester DVT Study. Arch Intern Med. 1991:151(5):933-8.

4. Cohen AT, Tapson VF, Bergmann JF, Goldhaber SZ, Kakkar AK, Deslandes B, et al. Venous thromboembolism risk and prophylaxis in the acute hospital care setting (ENDORSE study): a multinational cross-sectional study. Lancet 2008;371(9610):387-94

5. Nicolaides A, Breddin K, Carpentier P, Coccheri S, Conard J, De Stefano V, et al. Prevention and treatment of venous thromboembolism. International Consensus Statement (guidelines according to scientific evidence). Int Angiol. 2006;25(2):101-61.

6. Oger E. Incidence of venous thromboembolism: a community-based study in Western France. EPI-GETBP Study Group. Groupe d'Etude de la Thrombose de Bretagne Occidentale. Thromb Haemost. 2000;83(5):657-60.

7. Olié V, Chin F, Lamarche-Vadel A, De Peretti C. La maladie veineuse thromboembolique : patients hospitalisés et mortalité en France en 2010. Bull Epidémiol Hebd. 2013;33-34:417-23.

8. Tuppin $P$, de Roquefeuil $L$, Weill A, Ricordeau P, Merlière Y. French national health insurance information system and the permanent beneficiaries sample. Rev Epidemiol Sante Publique. 2010;54(4):286-90.

9. De Roquefeuil L, Studer A, Neumann A, Merlière Y. The Echantillon généraliste de bénéficiaires: representativeness, scope and limits. Pratiques et Organisation des Soins. 2009;40(3):213-23.

10. Institut National de la Statistique et des Etudes Economiques. Population totale par sexe et âge au 1er janvier 2011, France. 2011.

11. Benard E, Lafuma A, Ravaud P. Epidemiology of venous thromboembolic disease. Presse Med. 2005;34(6):415-9.

12. Guijarro R, Montes J, Sanroman C, Monreal M. Venous thromboembolism in Spain. Comparison between an administrative database and the RIETE registry. Eur J Intern Med. 2008;19(6):443-6.

13. Agnelli G, Buller HR, Cohen A, Curto M, Gallus AS, Johnson M, et al. Oral apixaban for the treatment of acute venous thromboembolism. N Engl J Med. 2013:369(9):799-808.

14. Bauersachs R, Berkowitz SD, Brenner B, Buller HR, Decousus H, Gallus AS, et al. Oral rivaroxaban for symptomatic venous thromboembolism. N Engl J Med. 2010;363(26):2499-510.

15. Buller HR, Prins $M H$, Lensin AW, Decousus $H$, Jacobson BF, Minar $E$, et al. Oral rivaroxaban for the treatment of symptomatic pulmonary embolism. N Engl J Med. 2012;366(14):1287-97.

16. Schulman S, Kearon C, Kakkar AK, Mismetti P, Schellong S, Eriksson H, et al. Dabigatran versus warfarin in the treatment of acute venous thromboembolism. N Engl J Med. 2009;361(24):2342-52.

17. Hansson PO, Sorbo J, Eriksson H. Recurrent venous thromboembolism after deep vein thrombosis: incidence and risk factors. Arch Intern Med. 2000;160(6):769-74.

18. Heit JA, Mohr DN, Silverstein MD, Petterson TM, O'Fallon WM, Melton 3rd LJ. Predictors of recurrence after deep vein thrombosis and pulmonary embolism: a population-based cohort study. Arch Intern Med. 2000;160(6):761-8.

19. Olie V, Zhu T, Martinez I, Scarabin PY, Emmerich J. Sex-specific risk factors for recurrent venous thromboembolism. Thromb Res. 2012;130(1):16-20.

20. Prandoni P, Noventa F, Ghirarduzzi A, Pengo V, Bernardi E, Pesavento R, et al. The risk of recurrent venous thromboembolism after discontinuing anticoagulation in patients with acute proximal deep vein thrombosis or pulmonary embolism. A prospective cohort study in 1,626 patients. Haematologica. 2007:92(2):199-205.

21. Nieto JA, De Tuesta AD, Marchena PJ, Tiberio G, Todoli JA, Samperiz AL, et al. Clinical outcome of patients with venous thromboembolism and recent major bleeding: findings from a prospective registry (RIETE). J Thromb Haemost. 2005:3(4):703-9.

22. Rodger M, Carrier M, Gandara E, Le Gal G. Unprovoked venous thromboembolism: Short term or indefinite anticoagulation? Balancing long-term risk and benefit. Blood Rev. 2010;24(4-5):171-8.

23. Cosmi B, Legnani C, Tosetto A, Pengo V, Ghirarduzzi A, Testa S, et al. Sex, age and normal post-anticoagulation D-dimer as risk factors for recurrence after idiopathic venous thromboembolism in the Prolong study extension. J Thromb Haemost. 2010;8(9):1933-42.
24. Huerta C, Johansson S, Wallander MA, Garcia Rodriguez LA. Risk factors and short-term mortality of venous thromboembolism diagnosed in the primary care setting in the United Kingdom. Arch Intern Med. 2007;167(9):935-43.

25. Sevestre MA, Quashie C, Genty C, Rolland C, Quere I, Bosson JL. Clinical presentation and mortality in pulmonary embolism: the Optimev study. J Mal Vasc. 2010;35(4):242-9.

26. Agence Nationale de Sécurité du Médicament et des produits de santé Prévention et traitement de la maladie thromboembolique veineuse en médecine. 2009

27. Nicolaides A, Fareed J, Kakkar A, Comerota AJ, Goldhaber SZ, Hull RD, et al. Prevention and treatment of venous thromboembolism: international consensus statement (guidelines according to scientific evidence). Int Angiol. 2013;32(2):132-9.

28. Kearon C, Akl EA, Comerota AJ, Prandoni P, Bounameaux H, Goldhaber SZ, et al. Antithrombotic therapy for VTE disease: Antithrombotic Therapy and Prevention of Thrombosis, 9th ed: American College of Chest Physicians Evidence-Based Clinical Practice Guidelines. Chest. 2012;141(2 Suppl):e419S-494S.

29. Agnelli G, Buller HR, Cohen A, Curto M, Gallus AS, Johnson M, et al. Apixaban for extended treatment of venous thromboembolism. N Engl J Med. 2013:368(8):699-708.

30. Romualdi E, Donadini MP, Ageno W. Oral rivaroxaban after symptomatic venous thromboembolism: the continued treatment study (EINSTEINextension study). Expert Rev Cardiovasc Ther. 2011;9(7):841-4.

31. Granger CB, Alexander JH, McMurray JJ, Lopes RD, Hylek EM, Hanna M, et al. Apixaban versus warfarin in patients with atrial fibrillation. N Engl J Med. 2011:365(11):981-92

32. Mega JL, Braunwald E, Wiviott SD, Bassand JP, Bhatt DL, Bode C, et al. Rivaroxaban in patients with a recent acute coronary syndrome. N Engl J Med. 2012;366(1):9-19.

33. Santos-Gallego CG, Badimón L, Badimón JJ. Perspectives: direct and specific inhibition of factor Xa: an emerging therapeutic strategy for atherothrombotic disease. Eur Heart J Suppl. 2014;16(Suppl A):A56-60

\section{Submit your next manuscript to BioMed Central and we will help you at every step:}

- We accept pre-submission inquiries

- Our selector tool helps you to find the most relevant journal

- We provide round the clock customer support

- Convenient online submission

- Thorough peer review

- Inclusion in PubMed and all major indexing services

- Maximum visibility for your research

Submit your manuscript at www.biomedcentral.com/submit 